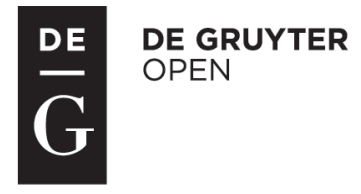

\title{
EFFECT OF DIFFERENT ENVIRONMENTAL CONDITIONS ON SOME HAEMATOLOGICAL PARAMETERS IN COW*
}

\author{
Giuseppe Mazzullo ${ }^{1}$, Claudia Rifici ${ }^{1}$, Floria Cammarata ${ }^{2}$, Gino Caccamo $^{3}$, Maria Rizzoํ, \\ Giuseppe Piccione ${ }^{1 \star}$ \\ ${ }^{1}$ Department of Veterinary Sciences, University of Messina. Polo Universitario dell'Annunziata, \\ 98168, Messina, Italy \\ ${ }^{2}$ Veterinary Practician, Palermo, Italy \\ ${ }^{3} \mathrm{PhD}$, Veterinary Practicioner, Modica (Ragusa), Italy \\ •Corresponding author: giuseppe.piccione@unime.it
}

\begin{abstract}
The aim of this study was to establish physiological responses of Piemontese cows to different environmental conditions (ambient temperature, relative humidity and temperature-humidity index). To this end, 43 clinically healthy Piemontese cows aged 2-12 years were used to evaluate the effect of environmental conditions on haematological parameters. For each period, ambient temperature and relative humidity were recorded by means of a data logger and the temperature-humidity index (THI) was calculated as indicator of thermal comfort for cattle. Blood samples were collected at 4 time points under different environmental conditions (T1, T2, T3 and T4) and analysed for haematological parameters. One way repeated measure analysis of variance showed a statistically significant effect of time $(\mathbf{P}<\mathbf{0 . 0 0 0 1})$ on $\mathrm{RBC}$, Hb, Hct, MCV, MCH, MCHC, PIt, WBC, neutrophils, lymphocytes, monocytes and eosinophils. The majority of haematological values obtained in the present study, even though within the physiological range for cattle, showed that variations in haematological parameters are related to changes in ambient temperature, relative humidity and temperature-humidity index. These results provide insight into the physiological responses of Piemontese cows to different environmental conditions, allowing to better evaluate its ability to adapt and cope with environmental stress.
\end{abstract}

Key words: cow, haematological parameters, ambient temperature, relative humidity, temperature-humidity index.

Seasonal and environmental changes may influence haematological values in domestic animals (Feldman et al., 2002). Thermal environment is a major factor that

\footnotetext{
*The paper was supported by funds of the Minister of Agricultural Policy and Forestry (MIPAF) OIGA DM 1882917818.
} 
can negatively affect cow performance, especially in animals of high genetic value. Increased livestock productivity is associated with increased production diseases that reflect changes in blood profile (Hewett, 1974). The variation in environmental variables such as ambient temperature, relative humidity, wind and rainfall were recognized as the potential hazards in livestock growth and production. Some species have evolved endogenous annual rhythmicity as an adaptive mechanism to react in advance to regular environmental changes associated with the seasons (Piccione et al., 2009).

Haematological measurements have been used to identify constraints on productivity in beef cattle (Grünwaldt et al., 2005). Blood parameter profile as animal response indicators can serve as the basis for diagnosis, treatment, and prognosis of diseases (Otto et al., 2000; Ndlovu et al., 2007). Stress-induced changes in immune function have been documented in cattle, with alterations to cell-mediated and humoral immunity having a significant impact on immunocompetence which may render an animal more susceptible to infection (Carroll and Forsberg, 2007). Exposure of cows to hot environment stimulates thermoregulatory mechanisms and produces reduction in the rates of metabolism, feed intake and productivity (Abdelatif and Alameen, 2012). In order to maintain homeothermy, an animal must be in thermal equilibrium with its environment, which includes radiation, air temperature, air movement and humidity (Kadzere et al., 2002). Heat stress occurs when any combination of environmental conditions causes the effective temperature of the environment to be higher than the animal's "thermoneutral" zone (Armstrong, 1994). Previous studies (Armstrong, 1994; Kadzere et al., 2002; Dikmen and Hansen, 2009) suggested that the temperature-humidity index (THI) could be used as indicator of thermal climatic conditions and of stress degree on cows.

Considering that environmental conditions are major physiological stressors which affect the animal's biological system, the objective of this study was to measure some haematological responses of Piemontese cows under different environmental conditions.

\section{Material and methods}

\section{Animals}

Forty-three Piemontese cows (2-12 years old, mean body weight $530 \pm 78 \mathrm{~kg}$ ), farmed in Sicily, Italy (latitude $36^{\circ} 53^{\prime} 27^{\prime} \mathrm{N}$, longitude $15^{\circ} 4^{\prime} 37^{\prime \prime} \mathrm{E}, 152 \mathrm{~m}$ above sea level), were used for this study. All animals were clinically healthy. Their health status was evaluated based on a thorough clinical exam. All animals were kept under natural photoperiod and environmental temperature. All cows were fed a constant diet composed of good-quality alfalfa hay and a concentrate mixture (oats $23 \%$, corn $36 \%$, barley $38 \%$, and mineral supplements $3 \%$ ). About $2.5 \mathrm{~kg} /$ animal of concentrate was distributed twice daily and water was available ad libitum. The concentrate was formulated to meet the requirements of beef cows based on the recommendations of 
the National Research Council (1996).

\section{Environmental conditions}

Environmental conditions recorded during the experimental period are presented in Table 1.

Table 1. Values of environmental conditions (ambient temperature, relative humidity, rainfall) and sunrise and sunset times during experimental periods

\begin{tabular}{|c|c|c|c|c|c|c|}
\hline \multirow{2}{*}{$\begin{array}{l}\text { Experimental } \\
\text { periods }\end{array}$} & \multicolumn{2}{|c|}{$\begin{array}{c}\text { Ambient temperature } \\
\left({ }^{\circ} \mathrm{C}\right)\end{array}$} & \multirow{2}{*}{$\begin{array}{l}\text { Relative humidity } \\
(\%)\end{array}$} & \multirow{2}{*}{$\begin{array}{l}\text { Rainfall } \\
(\mathrm{mm})\end{array}$} & \multirow[t]{2}{*}{ Sunrise time } & \multirow[t]{2}{*}{ Sunset time } \\
\hline & Min & Max & & & & \\
\hline $\mathrm{T} 1$ & 5 & 16 & 75 & 73 & $07: 12$ & $17: 08$ \\
\hline $\mathrm{T} 2$ & 12 & 24 & 19 & 68 & $04: 51$ & 19:02 \\
\hline $\mathrm{T} 3$ & 20 & 33 & 9 & 67 & $05: 19$ & $18: 48$ \\
\hline $\mathrm{T} 4$ & 10 & 20 & 62 & 75 & $06: 39$ & $16: 50$ \\
\hline
\end{tabular}

Thermal and hygrometric records were carried out for the whole study by means of a data logger with a high reading accuracy and resolution (Model Tinytag Ultra 2 Temperature/Relative Humidity Logger, Gemini Data Logger, West Sussex, United Kingdom; resolution: $0.01^{\circ} \mathrm{C} / 0.3 \% \mathrm{RH}$; accuracy: $\pm 1{ }^{\circ} \mathrm{C}$ from $-25^{\circ} \mathrm{C}$ to $+85^{\circ} \mathrm{C} /$ $\pm 3.0 \% \mathrm{RH}$ from $0 \%$ to $95 \% \mathrm{RH}$ ) placed inside the stanchion barn. For each experimental period, temperature-humidity index (THI), used as indicator of thermal comfort for cattle, was calculated using the U.S. Weather Bureau's Temperature Humidity Index Formula for bovine species (Potter and Jacobsen, 2000):

$$
\mathrm{THI}_{\left[{ }^{\circ} \mathrm{C}\right]}=T_{\text {ambient }}^{\circ}+(0.36 * \text { point of steam condensation })+41.5 \text {. }
$$

\section{Blood sampling and analysis}

Blood was collected by coccygeal venipuncture into vacuum tubes containing EDTA (Terumo Co., Tokyo, Japan). Whole blood was sampled at 4 time points under differing environmental conditions: T1, T2, T3 and T4. EDTA blood samples were refrigerated and analysed for complete blood count within $6 \mathrm{~h}$. From the collection, blood analysis was performed using the HeCo Vet $\mathrm{C}$ blood cell counter (SEAC, Florence, Italy). All samples were tested for red blood cell (RBC), haemoglobin concentration $(\mathrm{Hb})$, haematocrit $(\mathrm{Hct})$, mean corpuscular volume (MCV), mean corpuscular haemoglobin $(\mathrm{MCH})$, mean corpuscular haemoglobin concentrations (MCHC), platelet (Plt) and white blood cell (WBC). For leukocyte identification and counting, a manual analysis was performed on all samples. Blood smears were prepared immediately and air-dried. The Pappenheim method (May-Grünwald + Giemsa-Romanowsky staining) for the basal blood cell types characterization was used. The leukocyte differential counts were assessed by enumeration of 200 cells in each smear stained by the Pappenheim method (Konuk, 1981).

\section{Statistical analysis}

One-way repeated measure analysis of variance (ANOVA) was applied to deter- 
mine significant effects of time on haematological parameters studied. P value $<0.05$ was considered statistically significant. Bonferroni's multiple comparison test was applied for post hoc comparison. Data were analysed using statistical software Prism v. 4.00 (Graphpad Software Ldt., USA, 2003).

\section{Results}

The ambient temperature, relative humidity and THI observed during the four experimental periods (T1-T4) are shown in Figure 1.
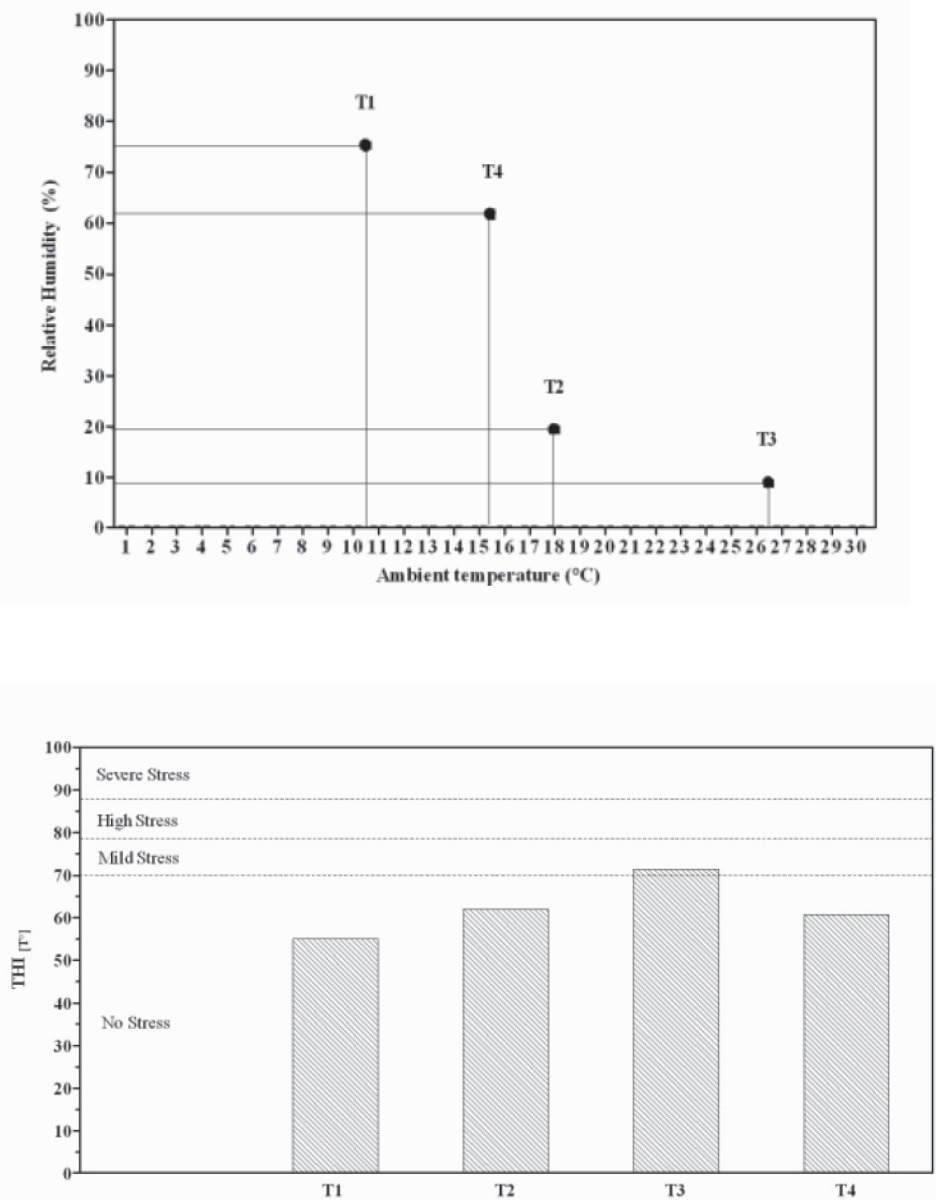

Figure 1. Mean values of ambient temperature (AT), relative humidity (RH) and temperature-humidity index recorded during experimental periods (T1-T4) 
All results are expressed as means \pm standard deviation (SD) in Table 2.

Table 2. Mean values $\pm \mathrm{SD}$ together with the relative statistical significance of haematological parameters and WBC differential cell counts observed in experimental periods

\begin{tabular}{l|c|c|c|c}
\hline \multirow{2}{*}{ Parameters } & \multicolumn{4}{c}{ Experimental periods } \\
\cline { 2 - 5 } & $\mathrm{T} 1$ & $\mathrm{~T} 2$ & $\mathrm{~T} 3$ & $\mathrm{~T} 4$ \\
\hline $\mathrm{RBC}(106 / \mu \mathrm{l})$ & $6.37 \pm 0.6$ & $5.98 \pm 0.7 \mathrm{~A}$ & $5.57 \pm 0.8 \mathrm{~A}, \mathrm{~B}$ & $5.75 \pm 0.8 \mathrm{~A}$ \\
$\mathrm{Hb}(\mathrm{g} / \mathrm{dl})$ & $10.48 \pm 1.1 \mathrm{C}$ & $9.97 \pm 1.1 \mathrm{C}$ & $9.35 \pm 1.2$ & $10.20 \pm 1.4 \mathrm{C}$ \\
Hct (\%) & $29.99 \pm 2.9 \mathrm{~B}, \mathrm{C}$ & $28.09 \pm 3.1$ & $27.51 \pm 3.4$ & $30.26 \pm 3.9 \mathrm{~B}, \mathrm{C}$ \\
MCV (fL) & $49.72 \pm 4.7 \mathrm{D}$ & $47.26 \pm 4.1 \mathrm{~A}, \mathrm{D}$ & $47.14 \pm 3.6 \mathrm{~A}, \mathrm{D}$ & $52.91 \pm 3.7$ \\
MCH (Pg) & $16.97 \pm 1.6 \mathrm{D}$ & $16.55 \pm 1.5 \mathrm{D}$ & $16.71 \pm 1.3 \mathrm{D}$ & $17.80 \pm 1.4$ \\
MCHC (g/dl) & $34.90 \pm 0.7 \mathrm{C}, \mathrm{D}$ & $35.51 \pm 0.7 \mathrm{~A}, \mathrm{C}, \mathrm{D}$ & $34.11 \pm 0.7 \mathrm{D}$ & $33.71 \pm 0.7$ \\
PLT (10 $/ \mu 1)$ & $310 \pm 103 \mathrm{C}$ & $289 \pm 91 \mathrm{C}$ & $222 \pm 68$ & $302 \pm 102 \mathrm{C}$ \\
WBC (10 $/ \mu 1)$ & $6.49 \pm 1.6$ & $8.04 \pm 1.1 \mathrm{~A}$ & $7.22 \pm 1.8 \mathrm{~A}$ & $6.30 \pm 1.8 \mathrm{C}$ \\
Lymphocytes (\%) & $50.95 \pm 5.9 \mathrm{C}$ & $50.70 \pm 5.6 \mathrm{C}$ & $59.64 \pm 4.3$ & $50.23 \pm 6.1 \mathrm{C}$ \\
Neutrophils (\%) & $41.21 \pm 7.7 \mathrm{C}$ & $40.07 \pm 5.8 \mathrm{C}$ & $31.96 \pm 4.6$ & $41.60 \pm 4.9 \mathrm{C}$ \\
Monocytes (\%) & $5.63 \pm 2.9$ & $4.00 \pm 1.9 \mathrm{~A}$ & $4.00 \pm 2.4$ & $4.74 \pm 2.7 \mathrm{~A}$ \\
Eosinophils (\%) & $2.21 \pm 1.0 \mathrm{~B}, \mathrm{C}$ & $5.23 \pm 2.3$ & $4.40 \pm 2.3$ & $3.43 \pm 1.8 \mathrm{~B}, \mathrm{C}$ \\
Basophils (\%) & $0.00 \pm 0.0$ & $0.00 \pm 0.0$ & $0.00 \pm 0.0$ & $0.00 \pm 0.0$ \\
\hline
\end{tabular}

Significance: A vs T1; B vs T2; C vs T3; D vs T4.

One-way ANOVA showed a statistically significant effect of time on the following parameters: $\mathrm{RBC}(\mathrm{P}<0.0001), \mathrm{Hb}(\mathrm{P}<0.0001)$, $\operatorname{Hct}(\mathrm{P}<0.0001), \mathrm{MCV}(\mathrm{P}<0.0001)$, MCH $(\mathrm{P}<0.0001)$, MCHC $(\mathrm{P}<0.0001)$, PLT $(\mathrm{P}<0.0001)$, WBC $(\mathrm{P}<0.0001)$, lymphocytes $(\mathrm{P}<0.0001)$, neutrophils $(\mathrm{P}<0.0001)$, monocytes $(\mathrm{P}<0.0001)$ and eosinophils $(\mathrm{P}<0.0001)$.

The application of Bonferroni's post-hoc comparison showed a statistically significant decrease in RBC values at T2, T3 and T4 compared to T1 and at T3 compared to $\mathrm{T} 2$. Hb concentrations were decreased at T3 compared to T1, T2 and T4. Hct levels exhibited lower values at T2 and T3 compared to T1 and T4. MCV levels exhibited higher values at T4 compared to T1, T2 and T3, and at T1 compared to T2 and T3. MCH values were higher at T4 compared to T1, T2 and T3. MCHC values were lower at T4 compared to T1, T2 and T3, at T3 compared to T1 and T2, and at T1 compared to T2. PLT levels exhibited lower values at T3 compared to T1, T2 and T4. WBC values were higher at T1 compared to T2 and T3, and at T4 compared to T3.

Lymphocyte values were higher at T3 compared to T1, T2 and T4, whereas at the same times neutrophil values were lower. Monocyte values were higher at T1 compared to T2 and T4. Eosinophil values were higher at T2 and T3 compared to $\mathrm{T} 1$ and $\mathrm{T} 4$. 


\section{Discussion}

The ambient temperature and THI recorded at T4 were within the upper critical zone (Figure 1). The ideal ambient temperature ("thermoneutral" zone) for a cow is between $5^{\circ} \mathrm{C}$ and $25 \mathrm{C}$ (Roenfeldt, 1998). As ambient temperature increases, it becomes more difficult for a cow to cool herself adequately and she enters heat stress. THI values of 70 or less are considered comfortable, 75-78 stressful, and values greater than 78 cause extreme distress with lactating cows being unable to maintain thermoregulatory mechanisms or normal body temperatures (Kadzere et al., 2002).

All results obtained in the present study are within the physiological range for cattle (Feldman et al., 2002). The haematological profile is important for indicating animal physiological changes (Jain, 1993). Usually, blood examination is performed such as screening procedure to assess general health and welfare, but haematological values indicated adaptability to adverse environmental conditions (Wood and Quiroz-Rocha, 2010).

The RBC count showed a significant decrease with concomitant significant changes in $\mathrm{Hb}$ and Hct during the warmest experimental periods (T3-T4). These data confirm results obtained in previous studies (Gutierrez-De Lar et al., 1971; Casella et al., 2013). These fluctuations during experimental periods can be attributed to changes in water balance. High environmental temperatures may lead to higher evaporative water loss through the skin surface, as well as the respiratory tract, thereby requiring compensatory water intake to regulate body temperature (Moustafa et al., 1977; Ogebe et al., 1996). The RBC, Hb and Hct heat-induced depression in cows exposed to high temperatures was probably associated to haemodilution effect, because more water was transported in circulatory system for evaporative cooling (El-Nouty et al., 1990; Koubkova et al., 2002). Together with the reduction in Hb and Hct, the significant decrease of MCV and MCH under high environmental temperatures (T3-T4) suggests that this adaptation is related to reduction in cellular oxygen requirements in order to reduce metabolic heat load (El-Nouty et al., 1990). However, decreased MCV may be seen in iron deficiency and chronic blood loss. Decreasing MCH may give an early clue of impending iron deficiency, since $\mathrm{MCH}$ falls before MCV and decreased MCHC occurs in iron deficiency anemia (Aengwanich et al., 2009). According to previous studies (El-Nouty et al., 1990; Mirzadeh et al., 2010; Casella et al., 2013), our results showed a decrease in PLT values associated with the rise in temperature (T3). This reduction can be due to high ambient temperature that is the main environmental stressing factor (Casella et al., 2013). In the present study WBC values were higher with increase in temperatures (T3), confirming results obtained in previous studies (Wegner et al., 1976; Abdelatif and Alameen, 2012). This could be due to release of corticosteroids or epinephrine hormones due to environmental heat stress which in turn increased leukocyte count (Jain, 1986). In accordance with Narayan et al. (2007), in the present study the lymphocyte values were increased in the hottest period, whereas the neutrophil values were decreased.

Possible causes of increase in eosinophils were parasite infestations, i.e. Babesia spp., Theileria spp., Anaplasma spp. and Trypanosoma spp. (Wood and QuirozRocha, 2010; Lempereur et al., 2012). Infection with many of these haemoparasite 
species results in a state of premunity, in which the host becomes a long-term, often asymptomatic carrier serving as a source of infection for the tick or insect vector (Bell-Sakyi et al., 2004). The increase in monocytes in the present study could be associated with increase in cortisol secretion. Monocytes respond to elevation in blood corticosteroid concentration, but species differences are seen with the type of response and the mechanism of monocytosis which occurs in some species is not known (Jain, 1993).

Although within the physiological range for cattle, our results showed variations in haematological parameters related to changes in ambient temperature, relative humidity and temperature-humidity index. Therefore, we can claim that the environmental conditions can influence the haematological profile of Piemontese cows. Major changes have been under the hottest environmental conditions; therefore suitable measures should be adopted to minimize environmental stress improving animal welfare.

\section{Acknowledgments}

The paper was supported by funds of the Minister of Agricultural Policy and Forestry (MIPAF) - OIGA DM 1882917818.

Authors would like to thank Dr. Salvatore Agricola (Veterinary Practicioner, Modica Ragusa, Italy) for his technical support.

\section{References}

A bde lat if A.M., A la me e n A.O. (2012). Influence of season and pregnancy on thermal and haemotological responses of crossbred dairy cows in a tropical environment. Global Veterinaria, 9: 334-340.

A engwanich W., Chantiratikul A., Pamok S. (2009). Effect of seasonal variations on hematological values and health monitor of crossbred beef cattle at slaughterhouse in northeastern part of Thailand. Am.-Eurasian J. Agric. Environ. Sci., 5: 644-648.

Armstrong D.V. (1994). Heat stress interaction with shade and cooling. J. Dairy Sci., 77: 2044-2050.

B e 11 - S a ky i L., K on e y E.B.M., D o g b e y O., Wa 1 ker A.R. (2004). Incidence and prevalence of tick-borne haemoparasites in domestic ruminants in Ghana. Vet. Parasitol., 124: 25-42.

C a r r o 11 J.A., F o r s b e r g N.E. (2007). Influence of stress and nutrition on cattle immunity. Vet. Clin. North Am. Food Anim. Pract., 23: 105-149.

Casella S., S ci anò S., Zumbo A., Monteverde V., F a zio F., Pic cione G. (2013). Effect of seasonal variations in Mediterranean area on haematological profile in dairy cow. Comp. Clin. Pathol., 22: 691-695.

D i k m e n S., H a n s e n P.J. (2009). Is the temperature-humidity index the best indicator of heat stress in lactating dairy cows in a subtropical environment? J. Dairy Sci., 92: 109-116.

E l-Nouty F.D., A l-Haidary A.A., S a lah M.S. (1990). Seasonal variation in hematological values of high- and average yielding Holstein cattle in semi-arid environment. J. King Saud. Univ., 2: $173-182$.

F e $1 \mathrm{~d}$ m a n B.F., Z in k1 J.G., J a in N.C. (2002). Schalm's Veterinary Hematology. Lippincott Williams and Wilkins, Philadelphia, Baltimore, New York, London, Buenos Aires, Hong Kong, Sydney, Tokyo.

Grünwaldt E.G., Guevara J.C., Estévez O.R., Vicente A., Rousselle H., Alcute n N., A guerregaray D., Stas i C.R. (2005). Biochemical and haematological measure- 
ments in beef cattle in Mendoza plain rangelands (Argentina). Trop. Anim. Health Prod., 37: $527-540$.

Gutierrez-De Lar J.H., Warnick A.C., C ow ley J.J., Hentges Jr. J.F. (1971). Environmental physiology in the sub-tropics. I. Effect of continuous environmental stress on some hematological values of beef cattle. J. Anim. Sci., 32: 968-973.

H e w e t t C. (1974). On the causes and effects of variations in the blood profile of Swedish dairy cattle. Acta Vet. Scand. Suppl., 50: 1-152.

J a in N.C. (1986). Schalm's Veterinary Haematology. 4th edition Lea and Febiger, Philadelphia, p. 236

J a in N.C. (1993). Essentials of Veterinary Hematology. Lea \& Febiger, Philadelphia.

Kadzer e C.T., Murph y M.R., S i 1 a n i k ove N., M a l t z E. (2002). Heat stress in lactating dairy cows: a review. Livest. Prod. Sci., 77: 59-91.

K o n u k T. (1981). Practical Physiology. 2nd Ed. Ankara University Press, Ankara.

Koubkova M., Knizkova I., Kunc P., Hartlova H., Flusser J., Dolezal O. (2002). Influence of high environmental temperatures and evaporative cooling on some physiological, hematological and biochemical parameters in high-yielding dairy cows. Czech J. Anim. Sci., 47: 309-318.

Lempereur L., Lebrun M., Cuvelier P., Sépult G., Caron Y., S a egerman C., S h i e ls B., L o s s o n B. (2012). Longitudinal field study on bovine Babesia spp. and Anaplasma phagocytophilum infections during a grazing season in Belgium. Parasitol. Res., 110: 1525-1530.

Mirzadeh Kh., Tabatabaei S., Bojarpour M., Mamoei M. (2010). Comparative study of hematological parameters according strain, age, sex, physiological status and season in Iranian cattle. J. Anim. Vet. Adv., 9: 2123-2127.

Moustafa T.H., A mer A.A., I s mail A.A. (1977). The effect of climatic changes on haemoglobin contents and corpuscular constituents on blood in cattle and buffaloes. Assiut Vet. Med. J., 4: $229-242$.

N a ray an U., S ingh D.V., Sharma R.J. (2007). Physiological responses in Holstein-Friesian crossbred lactating cows under heat stress ameliorating treatments. Indian J. Anim. Res., 41: $130-133$.

Ndlovu T., Chimony o M., O k oh A.I., Muchenje V., D zam a K., R a ats J.G. (2007). Assessing the nutrititional status of beef cattle: current practices and future prospects. Afr. J. Biotechnol., 6: 2727-2734.

Ogebe P.O., Ogunmodede K., McDowell L.R. (1996). Behavioral and physiological responses of Nigerian dwarf goats to seasonal changes of the humid tropics. Small Rumin. Res., 22: 213-217.

Ot to F., B a g g a s s e P., B og in E., Harun M., Vile la F. (2000). Biochemical blood profile of Angoni cattle in Mozambique. Israel Vet. Med. Assoc., 55: 1-9.

P i c c i o ne G., G i annett o C., C a sella S., C a ola G. (2009). Annual rhythms of some physiological parameters in Ovis aries and Capra hircus. Biol. Rhythm Res., 40: 455-464.

P o t t e r C.F., J a c o b s e n K.L. (2000). La riduzione dello stress da calore in un allevamento di bovine da latte del nord-est degli USA. Large Anim. Rev., 6: 35-41

R o e n f e ld t S. (1998). You can't afford to ignore heat stress. Dairy Manag., 35: 6-12.

W e g n e r T.N., S c h u h J.D., N e 1 s o n F.E., S t o t t G.H. (1976). Effect of stress on blood leucocyte and milk somatic cell counts in dairy cows. J. Dairy Sci., 59: 949-956.

W o o d D., Q u ir o z-R o ch a G.F. (2010). Normal hematology of cattle. In: Schalm's veterinary hematology. Weiss D.G., Wardrop K.J. (eds), 6th ed. Wiley, Philadelphia, pp. 829-835.

Received: 31 I 2014

Accepted: 8 V 2014 